\title{
Effects of fruit thinning on blueberry fruit maturation and quality
}

\author{
XianCong Zhang ${ }^{1,}$, , YaNan Wang ${ }^{2}$, Jun Wang ${ }^{3}$ and Xun Wang ${ }^{*}, b$ \\ ${ }^{1,4}$ Institute of Pomology \& Olericulture, Sichuan Agricultural University, Chengdu, Sichuan, China \\ ${ }^{2,3}$ College of Horticulture, Sichuan Agricultural University, Chengdu, Sichuan, China \\ a751814904@qq.com, dwangxun0104@hotmail.com
}

Keywords: Blueberry, Fruit thinning, Ear, Maturation, Quality

Abstract. Rabbiteye blueberry cv. 'Baldwin' has been thinned in varying degrees (20\%-40\% per ear) in fruit development period. We determined fruit maturation and qualities to evaluate thinning. Fruit qualities included vertical and horizontal diameter, single fruit weight, firmness, water content, soluble solids content, vitamin $\mathrm{C}$ content, titratable acid content and anthocyanins content. The result showed that, some fruits quality indexes increase, such as vertical and horizontal diameter, single fruit weight, firmness, soluble solids content, vitamin $\mathrm{C}$ content and anthocyanins content. Contrarily, water content and titratable acid content of mature fruit decreased. As the degrees of fruit thinning improving, blueberry fruits gain a more concentrated and earlier maturation. The reasonable fruit thinning significant improved blueberry fruit quality and put forward the maturation.

\section{Introduction}

Blueberry (Vaccinium spp.) is a kind of perennial deciduous or evergreen shrubs fruit trees. It belongs to family Vacciniaceae, genus Vaccinium ${ }^{[1]}$. At present, the domestic blueberry industry is still dominated by fresh fruit sales ${ }^{[2]}$. Blueberry is raceme plant, which fruits show a spike arrangement. However, the fruits of same strain or even same ear may be at different maturation stages, which cause great differences of fruit quality. It is necessary to artificial picking and grading selection blueberry fruits. As a cultivation measures, fruit thinning is effective to increase the economic value of fruits. After reasonable fruit thinning, the fruit volume and weight would increase, rotten fruit rate would decrease, and coloring and maturation would be in advance ${ }^{[3-6]}$.

In this research, rabbiteye blueberry cv. 'Baldwin' ears have been thinned in varying degrees (20\%-40\% per ear) in fruit development period. We determined the effects of fruit thinning on fruit quality. This study is aim to provide reference for the development of blueberry cultivation technology, explore a new way that ear becomes the unit of blueberry picking and selling.

\section{Materials and Methods}

Plant Materials. Three years old blueberry cv. 'Baldwin' was used. The plants are growing in Sichuan Chengdu, Pujiang blueberry orchard. Their growth status was the same.

Experimental Designs. We selected several ears of experimental group plants and marked them. Thinned the marked ears before the fruits entered the enlargement period (About $30 \mathrm{~d}$ after anthesis). Fruit thinning means that a certain percentage of fruits on every ear was artificial Tweezed, which ensures that the fruits on the same ear have the similar growth and enough space (The diseased fruits, the weak fruits, the flowers and the ovaries that are not yet enlarged were removed preferentially). Fruit thinning degree was divided into three levels: $20 \%$ of all fruits per ear (20\% thinning), 30\% of all fruits per ear (30\% thinning), $40 \%$ of all fruits per ear (40\% thinning). The control group was not thinned (CK).Mature blueberry fruits of all groups were harvested for experiment.

Fruit Maturation Statistics. When harvest, the number of all fruits every one marked ear was counted as A, the mature part of them was counted as B. The fruit maturing rate of this ear is equal to A divided by $\mathrm{B}$.

Fruit Appearance Qualities Estimation. The fruits were measured in weight,vertical diameter and horizontal diameter to estimate the appearance quality. 30 fruits per ear randomly selected from every 
treatment were wiped off the surface moisture and residues. The single fruit weight was determined by electronic balance. The vertical and horizontal diameters were determined by vernier caliper.

Fruit Internal Qualities Estimation. Fruits firmness, water content, soluble solids content, vitamin C content, titratable acid content and anthocyanin content were examined with 3 replicates. Firmness was measured with a handheld fruit firmness meter (FR-5105, Lutron). Water content were measured with atmospheric drying method. Soluble solids content were measured with a hand-held glucose meter (SKZ1019, SKZ). Vitamin C content were measured by 2,6-dichlorophenolindophenol titration method $^{[7]}$. Standard titrimetric method was used to detemine the titratable acids content. Anthocyanin content were determined by spectrophotometry ${ }^{[8]}$.

Statistical Methods. Statistical analysis of experimental data was performed using Excel 2007 and SPSS 18.0, and the single factor analysis of variance was performed using Duncan's new bipolar difference method.

\section{Results}

Effects of Fruit Thinning on Blueberry Maturation. The blueberry single ear fruit maturing rate of all fruit thinning treatments increased, which was significantly higher than that of control $(p<0.05)$ (Figure 1). Different degrees of fruit thinning gain different effects. With the increase of fruit thinning degrees, fruit maturing rate increase. It shows that fruit thinning could promote blueberry maturation and cause more concentrated maturation stage of same ear fruits.

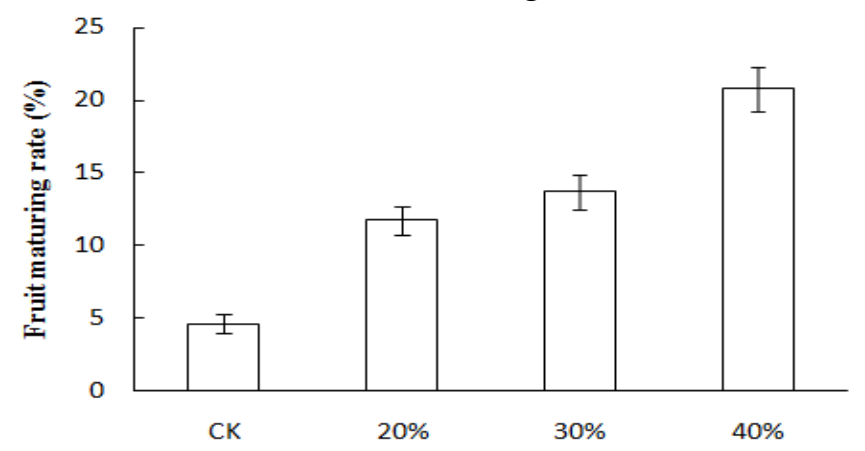

Figure. 1 Effects of fruit thinning on blueberry fruit maturing rate. CK is control. $20 \%, 30 \%$ and $40 \%$ are the treatments of corresponding fruit thinning degrees.

Effects of Fruit Thinning on Blueberry Appearance Qualities. The blueberry appearance qualities were improved by fruit thinning (Table 1). With the degree of fruit thinning increased, both of fruit vertical and horizontal diameters increased. Fruits of $40 \%$ thinning treatment was significantly higher than control on vertical and horizontal diameter $(\mathrm{p}<0.05)$. Single fruit weight of all fruit thinning treatments was significantly higher than that of control $(\mathrm{p}<0.05)$ and $40 \%$ thinning treatment is the best ( $21.87 \%$ heavier than control single fruit weight).

The increase of fruit vertical and horizontal diameter and single weight showed that the thinned fruit gained more adequate nutrient supply.

Table. 1 Effects of fruit thinning on blueberry vertical \& horizontal diameter and single fruit weight

\begin{tabular}{llll}
\hline Treatment & $\begin{array}{l}\text { Vertical } \\
\text { diameter }(\mathrm{mm})\end{array}$ & $\begin{array}{l}\text { Horizontal } \\
\text { diameter }(\mathrm{mm})\end{array}$ & $\begin{array}{l}\text { Single fruit } \\
\text { weight }(\mathrm{g})\end{array}$ \\
\hline $\mathrm{CK}$ & $13.92 \pm 0.40 \mathrm{~b}$ & $11.56 \pm 0.40 \mathrm{~b}$ & $1.48 \pm 0.05 \mathrm{c}$ \\
$20 \%$ thinning & $14.12 \pm 0.36 \mathrm{~b}$ & $12.25 \pm 0.69 \mathrm{ab}$ & $1.65 \pm 0.06 \mathrm{~b}$ \\
$30 \%$ thinning & $14.14 \pm 0.34 \mathrm{~b}$ & $12.34 \pm 0.29 \mathrm{ab}$ & $1.65 \pm 0.13 \mathrm{~b}$ \\
$40 \%$ thinning & $15.20 \pm 0.38 \mathrm{a}$ & $12.72 \pm 0.25 \mathrm{a}$ & $1.80 \pm 0.04 \mathrm{a}$ \\
\hline
\end{tabular}

Effects of Fruit Thinning on Blueberry Firmness and Water Content. As the table 2 showed, postharvest firmness of the thinned fruits was higher than that of control, but the differences between them did not reach significant level $(p<0.05)$. Similarly, water content of thinned fruits close to or less 
than that of control and there is also no significant difference between them $(\mathrm{p}<0.05)$. The effects of fruit thinning on firmness and water content were not obvious.

Table. 2 Effects of fruit thinning on blueberry firmness and water content

\begin{tabular}{lll}
\hline Treatment & Firmness $(\mathrm{Pa})$ & Water content $(\%)$ \\
\hline CK & $0.74 \pm 0.04 \mathrm{a}$ & $77.11 \pm 0.87 \mathrm{ab}$ \\
$20 \%$ thinning & $0.83 \pm 0.02 \mathrm{a}$ & $77.84 \pm 1.02 \mathrm{a}$ \\
$30 \%$ thinning & $0.81 \pm 0.11 \mathrm{a}$ & $76.41 \pm 0.55 \mathrm{ab}$ \\
$40 \%$ thinning & $0.80 \pm 0.13 \mathrm{a}$ & $75.83 \pm 0.88 \mathrm{~b}$ \\
\hline
\end{tabular}

Effects of Fruit Thinning on Blueberry Soluble Solids, Titratable Acid, Vitamin $\mathrm{C}$ and Anthocyanins Contents. Fruit thinning has different effects on soluble solids, titratable acid, vitamin $\mathrm{C}$ and anthocyanin content in blueberry fruits (Figure 2).Fruit thinning treatments are no very different from control on soluble solids content except for $40 \%$ thinning treatment, which is significantly higher than control $(\mathrm{p}<0.05)$. Fruit thinning did not have an impact on fruit titratable acid content until the thinning level reached $30 \%$. Titratable acid content of 30\% thinning treatment was $17.96 \%$ lower than that of control. Titratable acid content of $40 \%$ thinning treatment was $13.15 \%$ lower than that of control. Both of them have significant differences with control $(\mathrm{p}<0.05)$. With the degree of thinning increased, vitamin $\mathrm{C}$ content of blueberry fruit increased. Fruit vitamin $\mathrm{C}$ content of $40 \%$ thinning treatment was $37.99 \%$ higher than that of control, which reached a significant level $(\mathrm{p}<0.05)$. Thinning increased anthocyanin content in fruit. Compared with the control, the anthocyanin content of $20 \%$ and $40 \%$ fruit thinning treatment increased by $21.70 \%$ and $22.80 \%$ respectively, and reached a significant level $(\mathrm{p}<0.05)$.

Blueberry internal qualities could be improved by fruit thinning at the experiment set three levels.
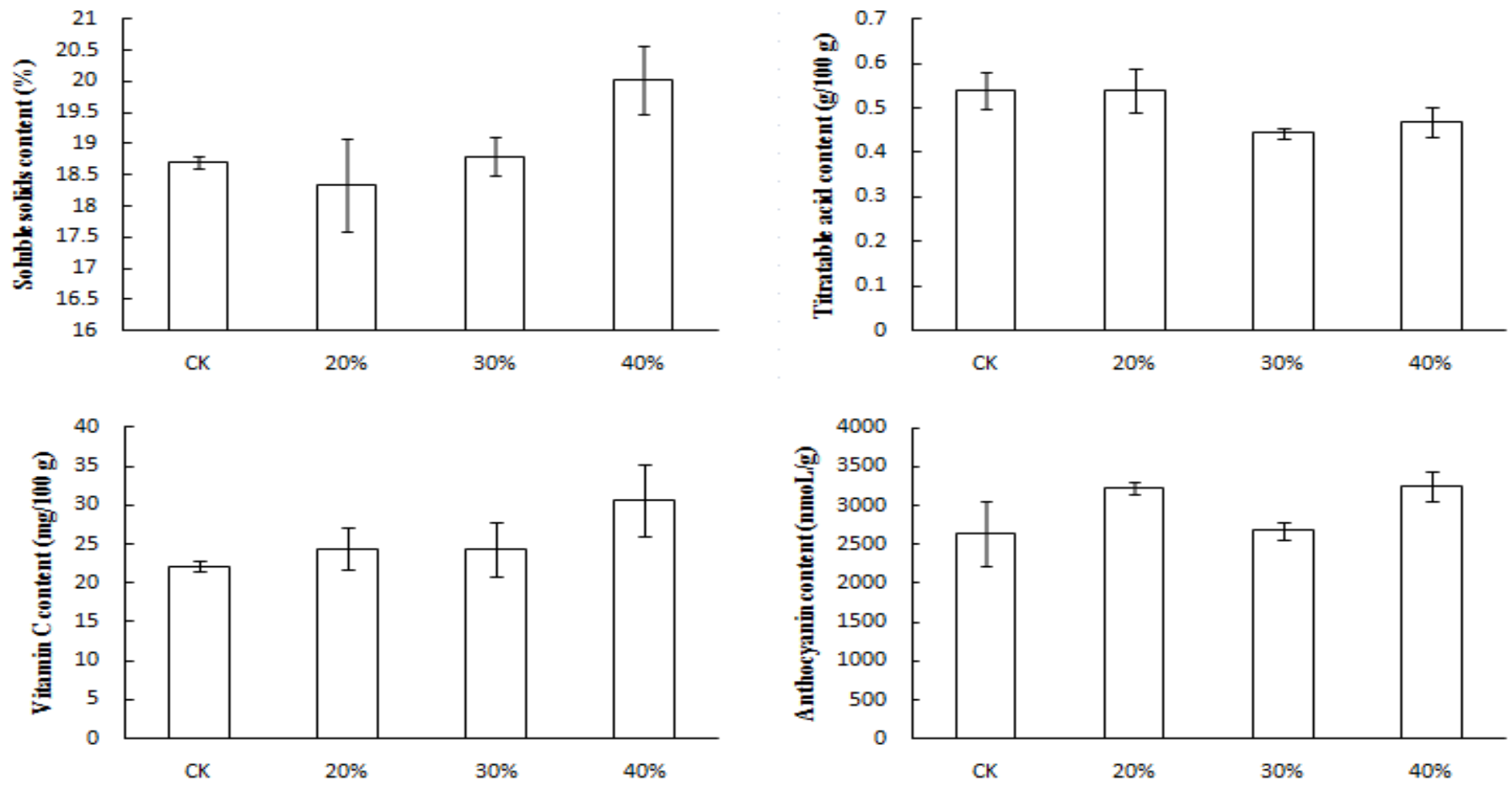

Figure. 2 Effects of fruit thinning on blueberry soluble solids, titratable acid, vitamin $C$ and anthocyanin content. CK is control. 20\%, 30\% and 40\% are the treatments of corresponding fruit thinning degrees.

\section{Discussions}

Fruit quality is influenced by many factors and fruit load is one of the important factors. Excessive fruit bearing lead to nutrient supply shortage of plant, which cause the volume decrease, slow maturation and low quality of fruits. Through the reduction of excessive fruit, abnormal fruit, small fruit and diseased fruit, the nutrient application and light transmission of plant could be improved, which 
promote the cell enlargement and the nutrition accumulation of fruit. Fruit thinning is widely researched in pomology, e.g. grape ${ }^{[9]}$, apple ${ }^{[10]}$ and plum $^{[11]}$. The way of thinning includes physical way and chemical way, too ${ }^{[12]}$. The results of our experiment showed that physical fruit thinning could obviously accelerate the ripening of blueberry and make sure that the maturation of all fruits on a single ear is almost identical. So far, it is still necessary for sellers to done artificial picking and grading selection many times in the production of blueberry. However, workers can cut the whole ear for sales at harvest time after fruit thinning, which not only reduces costs but also avoids the spread of diseases and pests in rotten fruit.

The results of our experiment confirmed that physical fruit thinning could obviously increase the size and weight of blueberry fruit. Meanwhile, fruit thinning could obviously increase the content of sugar, vitamin $\mathrm{C}$ and anthocyanin, reduce the content of acid. Blueberry fruit could have better taste, higher nutritional value and higher economic value after thinning.

\section{Conclusions}

With the degree of fruit thinning improved, blueberry could reach maturation stage earlier, which cause the concentrated maturation stage of whole ear fruits. The blueberry fruits thinned could up to standard for picking whole ear together. All qualities of fruit could be improved by fruit thinning. In the range of experiment set, higher thinning degree leads to better fruit quality. When the thinning degree is up to $40 \%$, fruit thinning could achieve the best effect for blueberry cultivation.

\section{References}

[1] Y.D. Li: Vaccinium spp.(blueberry) cultivation and utilization. Jilin Science and Technology Press Vol. 83-87 (2006) p. 4-6 (In Chinese)

[2] L.Y. Yang: Nutritional health function and product development of blueberry. Chinese Food and Nutrition Vol. 04 (2007) p. 26-27 (In Chinese)

[3] Z.R. Zhu: Study on tissue culture of Vaccinium rabbit blueberry. Guizhou Forestry Science and Technology Vol. 4 (2003) p. 20-22 (In Chinese)

[4] A.H. Pan: Key technological points of blueberry summer management. Xiandai Horticulture Vol. 15 (2013) p. 29-30 (In Chinese)

[5] Z. Wang: Plant physiology. China Agricultural Press (2014) p. 410-412 (In Chinese)

[6] J. Wang: The role of fruit thinning. Jilin Agriculture Vol. 6 (2001) p. 15 (In Chinese)

[7] J.K. Cao: The guidance of postharvest physiology and biochemistry of fruits and vegetables. China Light Industry Press (2007) (In Chinese)

[8] M.L. Zhao: Extraction and detection of procyanidins from blueberry. Jiangxi Chemical Industry Vol. 2 (2014) p.123-125 (In Chinese)

[9] L.X. Niu: Thinning flowers and fruit and grape quality. Northern Horticulture Vol. 9 (1991) p. 35-36 (In Chinese)

[10] W.X. Wang: Effects of different fruit thinning periods and fruit yield on fruit quality and flower bud differentiation. Liaoning Fruit Tree Vol. 01 (1982) p. 68-69 (In Chinese)

[11] D. Zhou: Effects of fruit thinning on quality and vegetative growth of plum. Southeast Horticulture Vol. 4(02) (2016) p.1-6 (In Chinese)

[12] D. Koron and M. Stopar: Effect of thinners on yield, fruit size and ripening time of highbush blueberry. Acta Horticulturae Vol. 715(715) (2006) p.273-278 